\title{
Fatty acids in intramuscular fat of lle de France lambs in two different production systems
}

\author{
Milan Margetín ${ }^{1,2}$, Marta Oravcová ${ }^{1}$, Jana Margetínová ${ }^{1}$, and Róbert Kubinec ${ }^{3}$ \\ ${ }^{1}$ Department for Animal Husbandry Systems, Breeding and Product Quality, National Agricultural and Food \\ Centre - Research Institute of Animal Production Nitra, 95141 Lužianky, Slovakia \\ ${ }^{2}$ Department of Animal Husbandry, Faculty of Agrobiology and Food Resources, Slovak University of \\ Agriculture in Nitra, 94976 Nitra, Slovakia \\ ${ }^{3}$ Institute of Chemistry, Faculty of Natural Sciences, Comenius University in Bratislava, 84215 Bratislava, \\ Slovakia
}

Correspondence: Marta Oravcová (oravcova@ vuzv.sk)

Received: 28 May 2018 - Accepted: 2 October 2018 - Published: 26 October 2018

\begin{abstract}
The fatty acid (FA) composition in the intramuscular fat (IMF) of the musculus longissimus dorsi (MLD) of Ile de France purebred lambs in two different production systems in Slovakia was evaluated using gas chromatography. In the first production system, lambs and ewes were assigned to pasture without access to concentrates $(\mathrm{P})$. In the second system, lambs and ewes were confined indoors with hay/silage and access to concentrates (S). An analysis of variance with the following factors was employed: production system, sex, and production system-sex interactions. The proportions of arachidonic, eicosapentaeonic, docosapentaeonic, and docosahexaenoic FAs, i.e. long-chain polyunsaturated FA (PUFA), were significantly higher in P lambs (1.83,

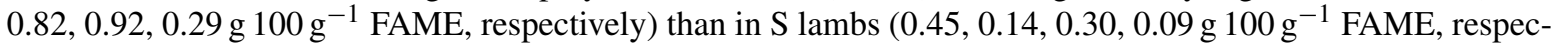
tively). The proportions of conjugated linoleic acid (CLA), n-6 PUFA, n-3 PUFA, and essential FA (linoleic

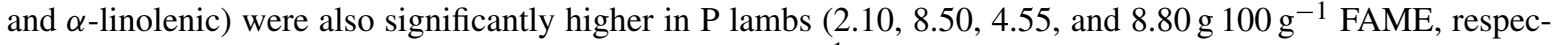

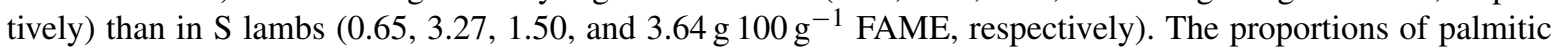
acid and myristic acid as important individual saturated FAs (SFA) were significantly higher in S lambs (28.51

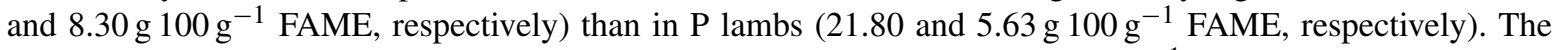

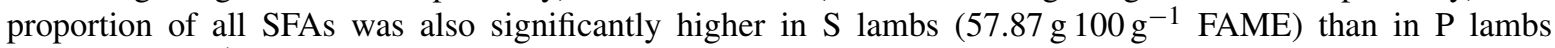

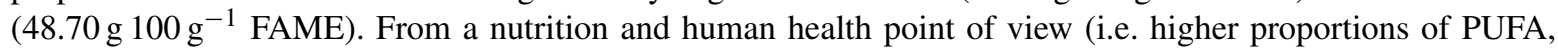
CLA, and essential FAs and lower proportions of SFAs), meat from P lambs was found to be more favourable and would be more highly recommended for consumption.
\end{abstract}

\section{Introduction}

In Slovakia, the breeding of meat and/or non-dairy dualpurpose sheep breeds that produce heavy lambs (carcass weight above $13 \mathrm{~kg}$ ) is increasing. The proportion of these breeds ranges from 10 to $15 \%$ of total number of sheep (from 37 to 55 thousand of a total 372 thousand animals in 2017). Lambs are produced using different production systems; however, knowledge about the effects of management and/or feed choice on lamb meat is only known for light lambs in Slovakia, with carcass quality, physicochemical characteristics, and fatty acid (FA) composition of light lambs having been previously studied (Margetín et al., 1993, 2014a, b).

Regardless of lamb type, research around the world is aimed at assessing the quality of lamb meat with respect to evaluating the proportions of essential FAs (linoleic acid and $\alpha$-linolenic acid) and other human health promoting FAs, such as eicosapentaenoic acid (EPA) and docosahexaenoic acid (DHA). These FAs all belong to the polyunsaturated FAs (PUFA) group and are found in intramuscular and extramuscular fat (Aurousseau et al., 2007a, b; Mortimer et al., 2014; Ponnampalam et al., 2014). The focus of exist- 
ing research has also been on evaluating the proportion of conjugated linoleic acid (CLA), mainly cis-9 trans-11 CLA isomer (rumenic acid), known for its anticarcinogenic, antiatherosclerotic, and antidiabetic effects (Raes et al., 2004; Nuernberg et al., 2005; Schmid et al., 2006; Serra et al., 2009; Gallardo et al., 2014). Regarding saturated FAs (SFA), high proportions of myristic and palmitic acids are assumed to increase the risk of cardiovascular diseases, whilst stearic acid, in comparison, is assumed have no effect on cholesterol levels (Howes et al., 2015). The ratio of PUFA / SFA, in the context of human health, is recommended to be above 0.7 , while the ratio of n-6/n-3 PUFA is recommended to be below 4 (Simopoulos, 2002; Wood et al., 2003; Howes et al., 2015). Furthermore, cis-isomers of FAs are assumed to have desirable health effects, whereas trans-isomers of FAs are assumed have undesirable health effects (EFSA, 2010), except for those found in products from ruminants (Howes et al., 2015).

Many studies have aimed at finding the potential benefits regarding the consumption of lamb meat (Mortimer et al., 2014; Ponnampalam et al., 2014). The emphasis of these studies has primarily been on assessing the proportions of n-6 PUFA and n-3 PUFA which are assumed to have antiinflammatory effects and to help protect against autoimmune diseases (Simopoulos, 2002; McAfee et al., 2010; Swanson et al., 2012). According to Australian and European standards, lamb meat is assumed to be an important source of $n-3$ PUFA when it contains a minimum of 30 to $40 \mathrm{mg}$ of longchain n-3 PUFA (EPA or DHA) per $100 \mathrm{~g}$ of meat (Ponnampalam et al., 2014; Howes et al., 2015). Fisher et al. (2000), Arsenos et al. (2006), Sinanoglou et al. (2013), and Ponnampalam et al. (2014) have indicated that consumer preferences mainly depend on the eating quality and nutrient value of the meat. Fatty acids occurring in fat contribute to the nutrient value of meat; however, the proportions of these FAs depend on the production system and the lamb feed used. Díaz et al. (2002, 2005), Aurousseau et al. (2004, 2007a, b), Nuernberg et al. (2005, 2008), Daley et al. (2010), and Howes et al. (2015) have reported that the FA composition in milk and meat depends on both pasture and concentrates. FA composition may also depend on genotype, although the genetic component of phenotypic variance is believed to be of lesser influence (Santos-Silva et al., 2002; Komprda et al., 2012; Ponnampalam et al., 2014).

In the 1970s and 1980s, Ile de France, as a dual-purpose breed, was mainly kept in order to improve the meat and wool production of traditional breeds in Slovakia. However, since the 1990s the Ile de France breed has been oriented to meat production; lamb feeding systems based on hay/silage and concentrates and systems based on grazing have both been considered. Differences in diet have enabled lamb birth to be postponed from winter to spring and natural pasture to be used. However, until now, no study has aimed at comparing the FA composition between grazing lambs and lambs fed with hay/silage and concentrates in Slovakia. Therefore, the objective of this study was to compare the FA composition in the intramuscular fat separated from the musculus longissimus dorsi (MLD) between Ile de France lambs from the two abovementioned production systems.

\section{Material and methods}

\subsection{Animals and production systems}

A total of 40 Ile de France purebred lambs kept either on pasture $(\mathrm{P})$ or in a stable $(\mathrm{S})$ were included in this experiment. Each group included 20 lambs: 13 males and 7 females. In the first production system, $\mathrm{P}$ lambs were born indoors (in April) and were moved to pasture shortly after parturition; the lambs were not separated from the ewes and were allowed to suckle milk. The lambs and ewes in this group were not fed on concentrates or hay/silage. The pasture was natural and was enriched with Poa pratensis, Festuca rubra, Lolium perenne, Trifolium pratense, Trifolium repens, and Lolium multiflorum, which are dietary sources of conjugated linoleic acid and other polyunsaturated acids according to Mel'uchová et al. (2008, 2009). The stocking rates for this group followed the standards (fence system, eight ewes with their lambs per hectare, as in Sharrow et al., 1981). In the second production system, S lambs were born indoors (in December/January) and housed with the ewes. The ewes' diet consisted of $1 \mathrm{~kg}$ maize and $1 \mathrm{~kg}$ alfalfa silage, in addition to $2 \mathrm{~kg}$ hay and 100$200 \mathrm{~g}$ of concentrate (ground barley and maize) per head per day. Approximately 2 weeks after birth, the lambs were moved to permanently opened nurseries, fed with commercial starter (NL min $190.0 \mathrm{~g} \mathrm{~kg}^{-1}$; fibre max $90.0 \mathrm{~g} \mathrm{~kg}^{-1}$; fat $\max 60.0 \mathrm{~g} \mathrm{~kg}^{-1}$; ash max $100 \mathrm{~g} \mathrm{~kg}^{-1}$; Ca min $11.2 \mathrm{~g} \mathrm{~kg}^{-1} ; \mathrm{P}$ $\min 6.1 \mathrm{~g} \mathrm{~kg}^{-1}$; Na min $2.0 \mathrm{~g} \mathrm{~kg}^{-1}+$ supplements), allowed to suckle milk, and offered hay ad libitum. Furthermore, from 2 months after birth, lambs were fed with a $200 \mathrm{~g}$ mixture of alfalfa and maize silage (ratio $2: 1$ ) per head per day.

Lambs were slaughtered in authorised slaughter houses run by the National Agricultural and Food Centre - Research Institute of Animal Production Nitra and the Slovak University of Agriculture in Nitra (identical slaughtering procedure). The average weights of $\mathrm{P}$ and $\mathrm{S}$ lambs at slaughter were $29.23 \pm 8.20$ and $32.2 \pm 2.62 \mathrm{~kg}$, respectively, and the average respective ages at slaughter were 106 days and 108 days. The average daily gains were $0.242 \pm 0.0341 \mathrm{~kg}$ (P lambs) and $0.264 \pm 0.0293 \mathrm{~kg}$ (S lambs).

The animals used in this study were treated in accordance with the current regulations and standards issued by the Ministry of Agriculture and Rural Development of the Slovak Republic. Manipulation methods were in accordance with the ICLAS Ethics and Animal Welfare Committee. 


\subsection{Analysis of fatty acids}

Twenty-four hours after slaughter, meat samples were taken from the MLD between the 9 and 13th vertebra. The analysis of the fatty acid (FA) composition in the intramuscular fat (IMF) of the MLD was undertaken in the laboratory of the Institute of Chemistry (Faculty of Natural Sciences) at Comenius University in Bratislava. After removing the epimysium, $100 \mathrm{~g}$ of the MLD was minced, vacuum packed, and stored at $-25^{\circ} \mathrm{C}$ until lipid analyses were carried out. The proportion of the individual FAs was analysed using capillary gas chromatography (GC). The lipids from $0.5 \mathrm{~g}$ meat samples were extracted using $2 \mathrm{~mL}$ chloroformmethanol mixtures $(2: 1 v / v)$ for $1 \mathrm{~h}$ on a rotary shaker. Next, $1 \mathrm{~mL}$ of saline water $(0.9 \% \mathrm{NaCl}$ in water) was added for better separation of the chloroform layer, and the sample was centrifuged at $2000 \mathrm{~g}$ for $5 \mathrm{~min}$. The lower $1 \mathrm{~mL}$ of the chloroform layers containing the extracted lipids was filtered through anhydrous sodium sulfate and dried under a nitrogen stream at $40{ }^{\circ} \mathrm{C}$. For the preparation of the FA methyl esters (FAME), the base-catalysed methylation procedure with a sodium methoxide in methanol was used. A $1 \mathrm{~mL}$ amount of $n$-hexane was added to the dried chloroform extract in a $2 \mathrm{~mL}$ autosampler vial and mixing was resumed. Next, $100 \mu \mathrm{L}$ of sodium methoxide $(0.5 \mathrm{M}$ solution in methanol) was added, mixed, and the vial contents were allowed to react for $15 \mathrm{~min}$ at $40^{\circ} \mathrm{C}$ with occasional mixing. The vial was cooled at $-20^{\circ} \mathrm{C}$ for $10 \mathrm{~min}$, before $60 \mu \mathrm{L}$ of oxalic acid $(0.5 \mathrm{~g}$ in $15 \mathrm{~mL}$ diethyl ether) was added and mixed thoroughly. The vial was centrifuged to settle the sodium oxalate precipitate, and the FAME solution was used directly for $\mathrm{GC}$ analyses. The analyses were performed on a $6890 \mathrm{~N}$ gas chromatograph (Agilent Technologies, Waldbronn, Germany) with a flame ionisation detector and a 5973 Network mass selective detector. A HP- 88 stationary phase capillary column $(100 \mathrm{~m} \times 0.25 \mathrm{~mm}$ i.d. $\times 0.2 \mu \mathrm{m}$ film thickness; J\&W Scientific, Agilent Technologies, CA, USA) was used for the FAME separation. The initial column temperature of the programmed run was set to $45^{\circ} \mathrm{C}$ and was held for $2 \mathrm{~min}$; this was followed by a step up ramp of $15^{\circ} \mathrm{C} \mathrm{min}^{-1}$ to $145^{\circ} \mathrm{C}$ and then of $5^{\circ} \mathrm{C} \min ^{-1}$ to $240^{\circ} \mathrm{C}$ and was held for $5 \mathrm{~min}$. Helium was used as the carrier gas with a linear velocity set at $20 \mathrm{~cm} \mathrm{~s}^{-1}$. Next, $2 \mu \mathrm{L}$ samples, which represented approximately $10 \mathrm{mg} \mathrm{mL}^{-1}$ FAME, were injected using a $50: 1$ split at an injection temperature of $300^{\circ} \mathrm{C}$. Separated FAs were identified using reference materials (Supelco 37 Component FAME Mix; PUFA No. 3 from menhaden oil, Sigma-Aldrich, Germany), published retention data, and mass spectrometric measurements. The chromatograms were quantitatively evaluated using an internal normalisation method (the area of each FAME peak in the chromatogram was multiplied by a response factor as a percentage of the total area of all FAME peaks) and published response factors of the flame ionisation detector for FAME (Ackman, 2002). The composition of the FAs was expressed in grams of each individual FAME per
$100 \mathrm{~g}$ of sum detected FAME. The average relative standard deviation of the FAME analysed with a proportion above

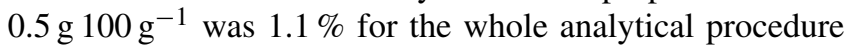
and the five replicate samples.

A total of 70 FAs were identified. The hypocholesterolaemic FA/hypercholesterolaemic FA ratio $(h / H$ index) was calculated according to Santos-Silva et al. (2002) and Sinanoglou (2013). The atherogenic index (AI) and thrombogenic index (TI) were calculated according to Ulbricht and Southgate (1991) and Sinanoglou et al. (2013), respectively.

\subsection{Statistical analysis}

Data were evaluated using an analysis of variance and a general linear model procedure as implemented in SAS (2009). Factors including the production system ( $\mathrm{P}$ lambs and $\mathrm{S}$ lambs), sex (males and females), and production system-sex interactions were studied. Least-squares means were compared using a Scheffe test.

\section{Results and discussion}

\subsection{Analysis of fatty acids}

\subsubsection{Effect of production system}

The composition of FAs identified in the IMF of the MLD as affected by production system is shown in Table 1. This factor significantly influenced the proportions of almost all of the FAs that were investigated. The prevailing individual saturated FAs (SFA) were palmitic acid (PA), stearic acid (SA), and myristic acid (MA). A crucial finding in this study was the significantly lower $(P<0.001)$ proportion of PA (which has undesirable effects on human health) in $\mathrm{P}$ lambs (21.80 $100 \mathrm{~g} \mathrm{~g}^{-1}$ FAME) in comparison with $\mathrm{S}$ lambs

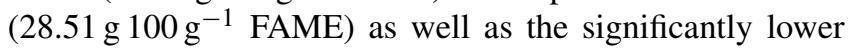
$(P<0.001)$ proportion of MA (which also has undesirable

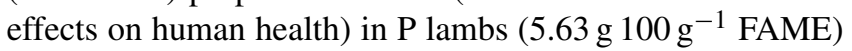

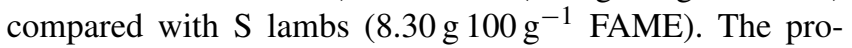
portion of SA (which has a neutral effect on total cholesterol) was significantly higher $(P<0.05)$ in $\mathrm{P}$ lambs com-

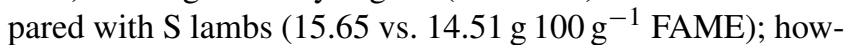
ever, the difference in SA between $\mathrm{P}$ and $\mathrm{S}$ lambs was relatively lower than the difference in PA and MA between lambs from the two respective production systems. When compared with values of PA, MA, and SA from the literature, a lower proportion of PA for Ile de France graz-

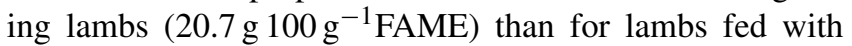

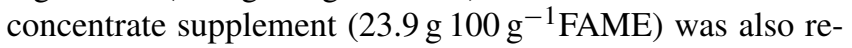
ported by Aurousseau et al. (2007a). The high proportion

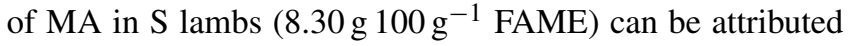
to a diet consisting of a relatively high portion of maize. When feed contains more energy, the intake of energy is higher and consequently de novo synthesis of MA and PA is also higher (Aurousseau et al., 2007a). Regarding MA in 
Table 1. Fatty acids in the intramuscular fat ( $\mathrm{g}_{100 \mathrm{~g}^{-1}}$ fatty acid methyl esters) of lamb meat dependent on production system and sex.

\begin{tabular}{|c|c|c|c|c|c|c|c|}
\hline \multirow[t]{2}{*}{ Fatty acids } & \multicolumn{2}{|c|}{ Production system } & \multicolumn{2}{|c|}{ Sex } & \multirow[t]{2}{*}{$\operatorname{PxS}(P)$} & \multirow[t]{2}{*}{ SEM } & \multirow[t]{2}{*}{$R^{2}$} \\
\hline & Pasture & Stable & Male & Female & & & \\
\hline C12:0 (lauric) & $0.75^{\mathrm{A}}$ & $1.06^{\mathrm{B}}$ & 0.94 & 0.87 & 0.0174 & 0.273 & 0.43 \\
\hline C14:0 (myristic) & $5.63^{\mathrm{A}}$ & $8.30^{\mathrm{B}}$ & 6.96 & 6.97 & 0.0096 & 1.307 & 0.64 \\
\hline C16:0 (palmitic) & $21.80^{\mathrm{A}}$ & $28.51^{\mathrm{B}}$ & 25.09 & 25.22 & 0.0050 & 1.496 & 0.87 \\
\hline C16:1 cis9 (palmitoleic) & 0.47 & 0.46 & 0.46 & 0.49 & 0.3432 & 0.063 & 0.15 \\
\hline $\mathrm{C} 17: 0$ (margaric) & $1.13^{\mathrm{A}}$ & $1.27^{\mathrm{B}}$ & 1.18 & 1.22 & 0.1786 & 0.089 & 0.51 \\
\hline C18:0 (stearic) & $15.65^{\mathrm{a}}$ & $14.51^{\mathrm{b}}$ & 15.29 & 14.88 & 0.2847 & 1.566 & 0.20 \\
\hline C18:1 trans9 (elaidic) & 0.28 & 0.28 & 0.26 & 0.30 & 0.3820 & 0.038 & 0.19 \\
\hline C18:1 cis9 (oleic) & $24.49^{\mathrm{A}}$ & $28.37^{\mathrm{B}}$ & $25.41^{\mathrm{A}}$ & $27.45^{\mathrm{B}}$ & 0.0459 & 1.743 & 0.59 \\
\hline C18:1 trans11 (TVA) & $4.05^{\mathrm{A}}$ & $1.13^{\mathrm{B}}$ & 2.56 & 2.62 & 0.7369 & 0.439 & 0.92 \\
\hline C18:2 n-6 (linoleic) & $6.42^{\mathrm{A}}$ & $2.73^{\mathrm{B}}$ & $5.00^{\mathrm{a}}$ & $4.14^{\mathrm{b}}$ & 0.0934 & 1.226 & 0.75 \\
\hline C18:3 n-6 (GLA) & $0.05^{\mathrm{A}}$ & $0.04^{\mathrm{B}}$ & 0.05 & 0.04 & 0.0953 & 0.013 & 0.37 \\
\hline C18:3 n-3 (ALA) & $2.38^{\mathrm{A}}$ & $0.91^{\mathrm{B}}$ & $1.78^{\mathrm{A}}$ & $1.51^{\mathrm{B}}$ & 0.1605 & 0.274 & 0.90 \\
\hline $\mathrm{C} 18: 2$ cis 9 trans 11 (RA) & $1.82^{\mathrm{A}}$ & $0.56^{\mathrm{B}}$ & $1.06^{\mathrm{A}}$ & $1.33^{\mathrm{B}}$ & 0.0112 & 0.245 & 0.88 \\
\hline C20:4 n-6 (arachidonic) & $1.83^{\mathrm{A}}$ & $0.45^{\mathrm{B}}$ & $1.43^{\mathrm{a}}$ & $0.85^{\mathrm{b}}$ & 0.1203 & 0.799 & 0.54 \\
\hline C20:5 n-3 (EPA) & $0.82^{\mathrm{A}}$ & $0.14^{\mathrm{B}}$ & 0.60 & 0.36 & 0.1595 & 0.356 & 0.57 \\
\hline C22:5 n-3 (DPA) & $0.92^{\mathrm{A}}$ & $0.30^{\mathrm{B}}$ & 0.69 & 0.51 & 0.2476 & 0.295 & 0.60 \\
\hline C22:6 n-3 (DHA) & $0.29^{\mathrm{A}}$ & $0.03^{\mathrm{B}}$ & 0.22 & 0.16 & 0.4424 & 0.127 & 0.45 \\
\hline
\end{tabular}

PxS: interaction between production system and sex; $P$ : probability level; SEM: standard error of mean. TVA: trans-vaccenic acid; ALA: $\alpha$-linolenic acid; GLA: $\gamma$-linolenic acid; RA: rumenic acid; EPA: eicosapentaeonic acid; DPA: docosapentaeonic acid; DHA: docosahexaeonic acid. A, B : differences at $P<0.001 ;{ }^{\mathrm{a}, \mathrm{b}}$ : differences at $P<0.05$.

S lambs, Díaz et al. (2005) reported both higher and lower

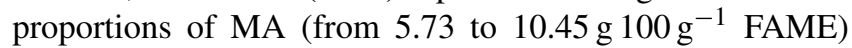
for heavy lambs of various breeds and crosses fed on either grass, combined grass-concentrate, or concentrate in Spain, Germany, Great Britain, and Uruguay (combined effect of breed, diet, sex, and husbandry). Daley et al. (2010) reported that grass-finished beef tends to have higher proportions of cholesterol neutral SA and lower proportions of cholesterol-elevating SFAs (MA and PA). In contrast to findings regarding SA in this study $\left(15.65\right.$ vs. $14.51 \mathrm{~g} 100 \mathrm{~g}^{-1}$ FAME in P and S lambs), Cividini et al. (2014) observed no statistical difference in the proportion of SA between pas-

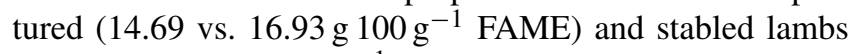

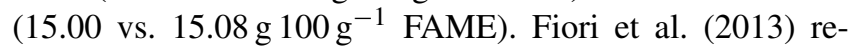
ported higher proportions of PA (23.47 vs. $25.07 \mathrm{~g} 100 \mathrm{~g}^{-1}$

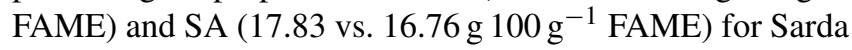
$x$ Ile de France crossbreeds that were either grazing or fed with hay and concentrates, which is in contrast to the $\mathrm{P}$ and $\mathrm{S}$ lambs from this study. According to Howes et al. (2015), animals on feedlot or grain-based diets produce higher levels of SA and PA than those on pasture-based diets with minimal amounts of grain. In this study, the proportion of margaric

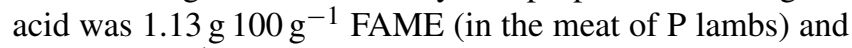

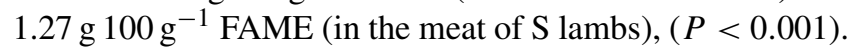
When comparing these values with the literature, they are more than twofold higher than Costa et al. (2015) reported

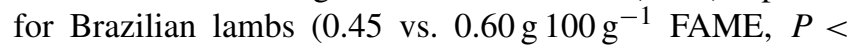

0.05 ) fed on a diet comprising $20: 80$ and $50: 50$ ratios of forage/concentrate, and slaughtered at live weight of $36 \mathrm{~kg}$.

Regarding individual monounsaturated FAs (MUFA), a lower $(P<0.001)$ proportion of oleic acid $(\mathrm{OA})$ was found

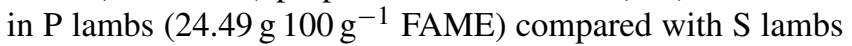

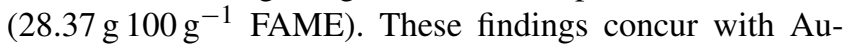
rousseau et al. (2007a), who reported that the proportion

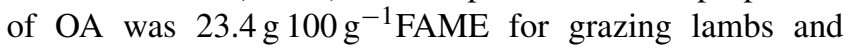

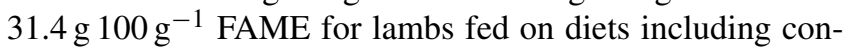
centrates. Aurousseau et al. (2007a) also indicated that the proportion of OA is mainly affected by feeding. Oleic acid is a FA that is mobilised from body fat, and its higher proportion in $\mathrm{S}$ lambs is probably linked to the higher daily gains of these lambs. Furthermore, concentrates in the diets of lambs are expected to increase the absorption of OA, which is found in cereal grains (Jenkins, 1994). Silva Sobrinho et al. (2014) reported higher proportions of OA (40.25

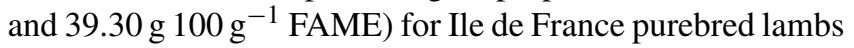
on a diet with a forage/concentrate ratio of $50: 50$, which was also enriched by various portions of mulberry hay, compared with $\mathrm{P}$ and $\mathrm{S}$ lambs in this study. No differences $(P>0.05)$ in the proportions of elaidic acid (EA) and palmitoleic acid were found; these proportions were either equal $(0.28 \mathrm{~g} 100$ g-1 FAME) or almost equal (0.47 and $0.46 \mathrm{~g} 100 \mathrm{~g}-1$ FAME). Conversely, Cividini et al. (2014) reported significant differences $(P<0.05)$ in the proportions of EA between pastured and stabled Jezersko-Solčava lambs $\left(0.28\right.$ and $0.30{\mathrm{~g} 100 \mathrm{~g}^{-1}}^{-1}$

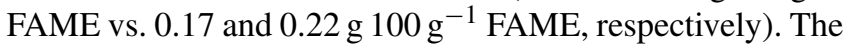


proportion of trans-vaccenic acid (TVA), which is the most important precursor of conjugated linoleic acid (CLA), was

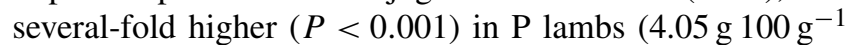

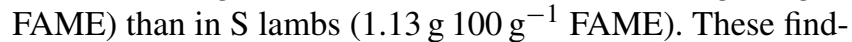
ings agree with Nuernberg et al. (2005), Aurousseau et al. (2007a), and Cividini et al. (2014), who reported a significantly higher proportion of TVA in grass feed lambs than in lambs fed on a diet including concentrates. According to Daley et al. (2010), grass-based diets also enhance total CLA isomers and TVA in beef. Vaccenic acid (VA) in ruminant meat is considered to have an anti-carcinogenic effect (Pariza et al., 2001) and a possible positive role in the endogenous synthesis of CLA (Cividini et al., 2013). The higher proportion of TVA in grazing lambs is probably a result of the fact that VA, among others, originates as a main intermediate during the bio-hydrogenation of $\alpha$-linolenic acid (ALA), which occurs in grass.

Regarding individual polyunsaturated FAs (PUFA), the proportion of essential linoleic acid (LA) was about twofold

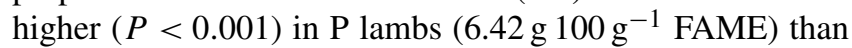

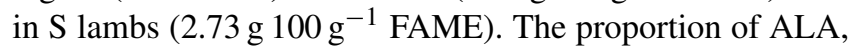
which is also an essential FA that is mainly found in pasture feed (Mel'uchová et al., 2009), was about twofold higher

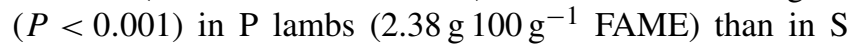

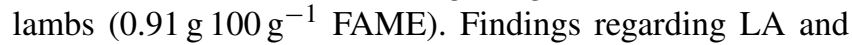
ALA from this study agree with Cividini et al. (2014) but disagree with Aurousseau et al. (2007a) - Aurousseau et al. (2007a) reported the highest proportion of LA in lambs

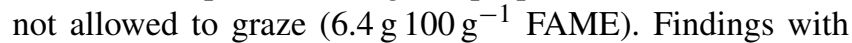
regards to the higher proportion of ALA in grazing lambs from this study agree with Wood et al. (2008) and Serra et al. (2009); both of these studies indicated that grass is rich in this particular FA. The proportion of rumenic acid (RA) was significantly higher $(P<0.001)$ in $P$ lambs $\left(1.82{\mathrm{~g} 100 \mathrm{~g}^{-1}}^{-1}\right.$

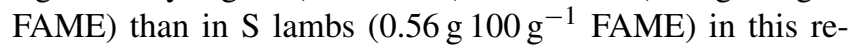
search which agrees with Aurosseau et al. (2007a), although these authors reported a slightly lower difference in RA be-

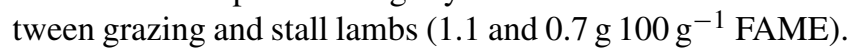
The proportions of arachidonic acid (AA), eicosapentaenoic acid (EPA), docosapentaeonic acid (DPA), and docosahexaenoic acid (DHA), which are important from a human health point of view, are of great interest; these acids displayed significantly higher proportions $(P<0.001)$ in $\mathrm{P}$ lambs $(1.83$,

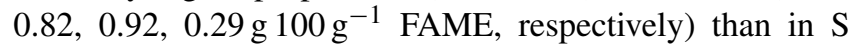

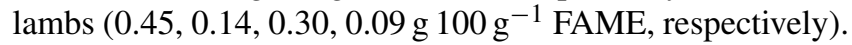
These findings agree with Daley et al. (2010) and Howes et al. (2015) who reported that the dietary source of lambs may influence the proportion of these FA in their meat - with grazing lambs showing higher proportions of the abovementioned beneficial FAs. The proportions of AA, EPA, and DPA in $P$ lambs were found to be higher than those reported by Yousefi et al. (2012) for the tailed Zel breed in Iran (0.98,

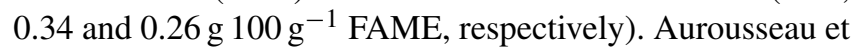
al. (2007a) also reported higher proportions of AA, EPA, DPA, and DHA for lambs on grass than for lambs on ei- ther pasture feeding combined with stall-finishing on concentrates and hay or exclusively on concentrates and hay. The proportions of $\gamma$-linolenic acid were 0.05 and $0.04{\mathrm{~g} 100 \mathrm{~g}^{-1}}^{-1}$ FAME in meat of $\mathrm{P}$ and $\mathrm{S}$ lambs, respectively, and were about twofold lower when compared with results reported by Cividini et al. (2014) for Jezersko-Solčava lambs (between 0.09

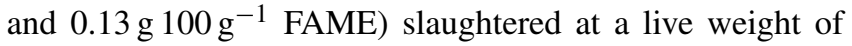
between 30 and $38 \mathrm{~kg}$.

\subsubsection{Effect of sex}

The composition of FAs as affected by sex is shown in Table 1. No significant differences were found in the proportions of MA, PA, SA, lauric, and margaric acids between males and females. Conversely, Arsenos et al. (2006) reported a significant difference in the proportion of SA dependent on sex. Regarding individual MUFA, the highest significant difference $(P<0.001)$ in the proportions

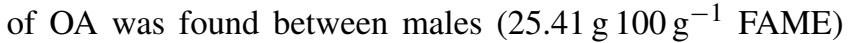

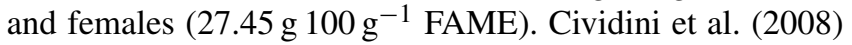
reported slightly higher proportions of OA for JezerskoSolčava female and male lambs (31.90 and $28.37{\mathrm{~g} 100 \mathrm{~g}^{-1}}^{-1}$ FAME, respectively) and assumed that differences in the composition of this FA between the sexes were due to the different content of intramuscular fat. Both LA and ALA displayed higher proportions in males than females (5.00

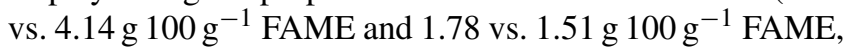
respectively), which is probably the result of differences in male and female vitality, voracity, and metabolism (Margetín et al., 2014b). Cividini et al. (2008) also reported higher proportions of LA and ALA for males than for females

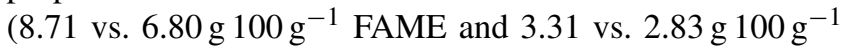
FAME, respectively). In addition, significantly different pro-

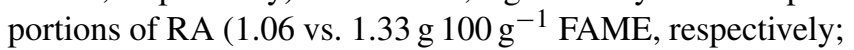

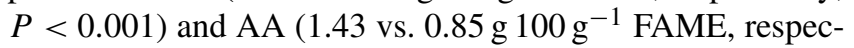
tively; $P<0.05)$ were found between males and females in this study. The findings of this study regarding the proportions of AA roughly agreed with Cividini et al. (2008):

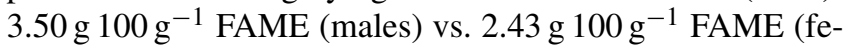
males).

The production system-sex interaction differed significantly $(P<0.05 ; P<0.001)$ mainly with respect to the proportions of individual SFAs (lauric acid, MA, PA). To the authors' best knowledge, no studies investigating the effect of production system and sex interaction currently exist in the literature; therefore, respective comparisons could not be carried out.

\subsection{Analysis of groups of fatty acids, their ratios, and indexes}

\subsubsection{Effect of production system}

The proportions of FA groups believed to affect human health (Wood et al., 2003; Sinanoglou et al., 2013), their ratios, and indexes are shown in Table 2. Lamb meat is as- 
Table 2. Fatty acid groups ( $\mathrm{g} 100 \mathrm{~g}^{-1}$ fatty acid methyl esters), their ratios, and indexes dependent on production system and sex.

\begin{tabular}{|c|c|c|c|c|c|c|c|}
\hline \multirow[t]{2}{*}{ Fatty acids } & \multicolumn{2}{|c|}{ Production system } & \multicolumn{2}{|c|}{ Sex } & \multirow[t]{2}{*}{$\operatorname{PxS}(P)$} & \multirow[t]{2}{*}{ SEM } & \multirow[t]{2}{*}{$R^{2}$} \\
\hline & Pasture & Stable & Male & Female & & & \\
\hline SFA $^{1}$ & $48.70^{\mathrm{A}}$ & $57.87^{\mathrm{B}}$ & 53.46 & 53.11 & 0.0133 & 3.041 & 0.78 \\
\hline MUFA $^{2}$ & 34.08 & 35.53 & $33.52^{\mathrm{A}}$ & $35.86^{\mathrm{B}}$ & 0.1300 & 2.306 & 0.25 \\
\hline PUFA $^{3}$ & $17.21^{\mathrm{A}}$ & $6.80^{\mathrm{B}}$ & 5.07 & 5.23 & 0.1522 & 2.971 & 0.79 \\
\hline Trans-UFA ${ }^{4}$ & $7.04^{\mathrm{A}}$ & $3.27^{\mathrm{B}}$ & 13.01 & 11.00 & 0.9466 & 0.635 & 0.91 \\
\hline Cis-UFA ${ }^{5}$ & $29.28^{\mathrm{A}}$ & $32.36^{\mathrm{B}}$ & $29.59^{\mathrm{A}}$ & $32.05^{\mathrm{B}}$ & 0.1492 & 2.010 & 0.47 \\
\hline $\mathrm{BCFA}(\text { iso, anteiso })^{6}$ & $1.92^{\mathrm{A}}$ & $2.43^{\mathrm{B}}$ & 2.11 & 2.24 & 0.0768 & 0.194 & 0.71 \\
\hline Essential FA (LA + ALA) & $8.80^{\mathrm{A}}$ & $3.64^{\mathrm{B}}$ & $6.78^{\mathrm{a}}$ & $5.66^{\mathrm{b}}$ & 0.0919 & 1.447 & 0.80 \\
\hline$n-6$ PUFA $^{7}$ & $8.50^{\mathrm{A}}$ & $3.27^{\mathrm{B}}$ & $6.64^{\mathrm{a}}$ & $5.14^{\mathrm{b}}$ & 0.0933 & 2.055 & 0.69 \\
\hline$n-3$ PUFA $^{8}$ & $4.55^{\mathrm{A}}$ & $1.50^{\mathrm{B}}$ & $3.41^{\mathrm{a}}$ & $2.65^{\mathrm{b}}$ & 0.1667 & 1.008 & 0.75 \\
\hline CLA $^{9}$ & $2.10^{\mathrm{A}}$ & $0.65^{\mathrm{B}}$ & $1.23^{\mathrm{A}}$ & $1.52^{\mathrm{B}}$ & 0.0121 & 0.266 & 0.90 \\
\hline PUFA / SFA & $0.36^{\mathrm{A}}$ & $0.12^{\mathrm{B}}$ & 0.26 & 0.21 & 0.1062 & 0.080 & 0.75 \\
\hline$\sum n-6 / \sum n-3$ PUFA & $1.86^{\mathrm{A}}$ & $2.23^{\mathrm{B}}$ & 1.99 & 2.07 & 0.1635 & 0.331 & 0.22 \\
\hline$\overline{\mathrm{LA}} / \mathrm{ALA}$ & 2.68 & 3.06 & 2.82 & 2.91 & 0.1938 & 0.588 & 0.11 \\
\hline LC n-6 / LC n-3 PUFA 10 & 0.92 & 0.92 & 0.97 & 0.88 & 0.3079 & 0.166 & 0.10 \\
\hline AI (atherogenic index) & $0.97^{\mathrm{A}}$ & $1.58^{\mathrm{B}}$ & 1.30 & 1.25 & 0.0031 & 0.230 & 0.74 \\
\hline TI (thrombogenic index) & $1.24^{\mathrm{A}}$ & $2.13^{\mathrm{B}}$ & 1.68 & 1.68 & 0.0224 & 0.228 & 0.83 \\
\hline$h / H^{11}$ index & $1.38^{\mathrm{A}}$ & $0.90^{\mathrm{B}}$ & 1.17 & 1.11 & 0.0076 & 0.200 & 0.70 \\
\hline \multicolumn{8}{|c|}{ 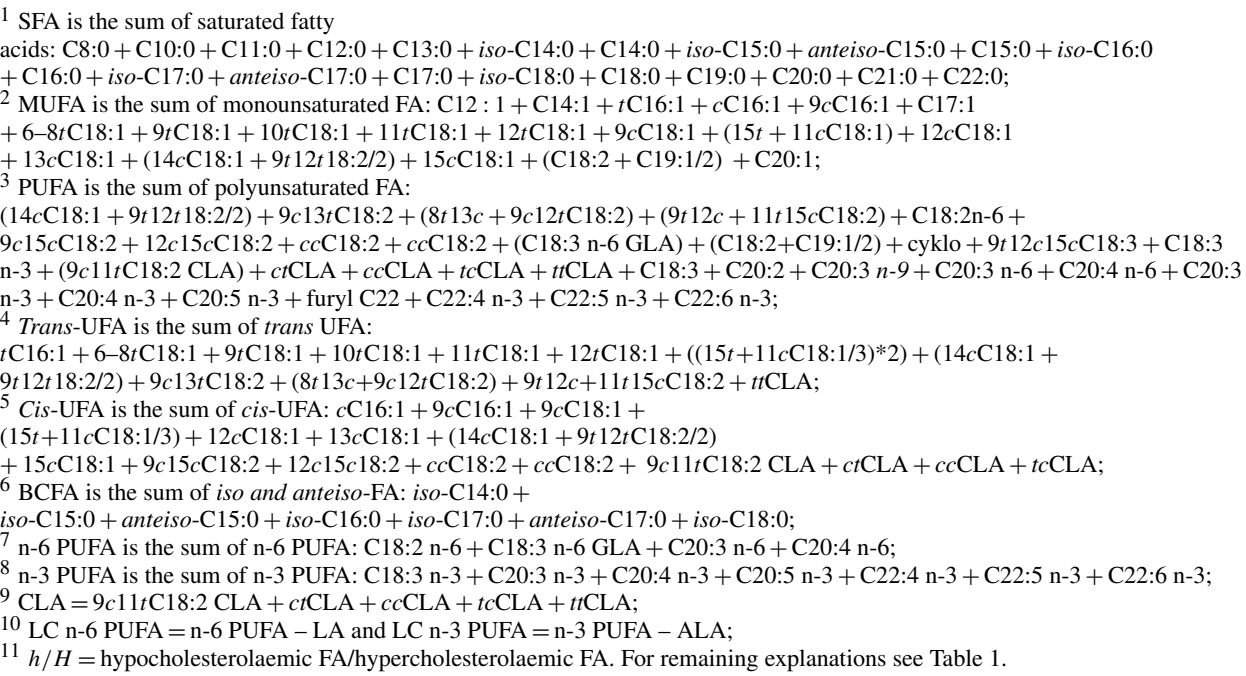 } \\
\hline
\end{tabular}

sumed to be highly nutritious and easy digestible (Milewski, 2006; Nuernberg et al., 2008). Some doubts about the health effects of the consumption of red meat (including lamb meat) and its lipid composition have arisen due to the relatively high proportion of SFAs and relatively low proportion of PUFAs (McAfee et al., 2010; Howes et al., 2015). The proportion of the SFA group was significantly higher

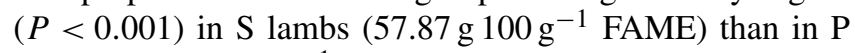

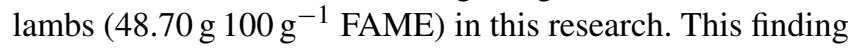
agrees with studies such as Díaz et al. (2005), Aurousseau et al. (2007a), and Yousefi et al. (2012), which found that the dietary source of lambs is the reason for this difference-less SFA was found in grazing lambs. When compared with light lambs, the content of SFA was found to be higher in heavy lambs (in both $\mathrm{P}$ and $\mathrm{S}$ lambs), most likely due to the fact that light lambs are less fatty. In addition, the lower content of SFA in light lambs probably results from their diet which mainly consists of milk (Lanza et al., 2006; Margetín et al., 2014a).

The proportion of the PUFA group was significantly

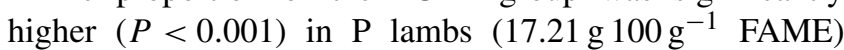

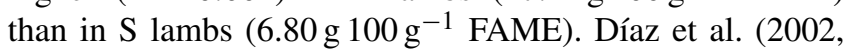
2005), Aurousseau, et al. (2004, 2007a, b), and Nuernberg et al. (2008) also reported that the proportion of these FAs was higher in lambs on pasture than in lambs fed with hay and concentrates. Moreover, Fiori et al. (2013) found the proportion of the PUFA group to be higher in lambs on pas-

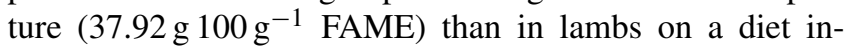




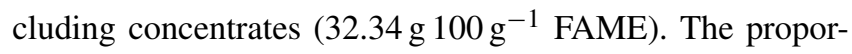
tion of CLA was significantly higher $(P<0.001)$ in $\mathrm{P}$ lambs

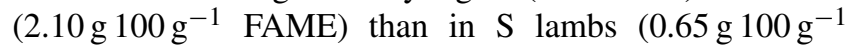
FAME). This agreed with the fact that grass-based diets were shown to enhance total CLA in meat (Daley et al., 2010). When comparing the findings from this study with Raes et al. (2004), who recommended that CLA in lamb

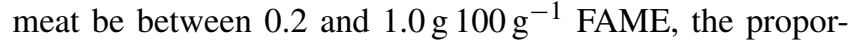
tion of CLA in P lambs exceeded (was more than double) the recommended value. The proportion of essential FAs as a sum of LA and ALA was about twofold higher

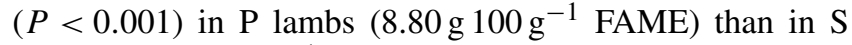

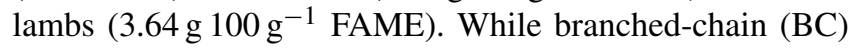
FAs mainly occur in milk lipids, it is important to emphasise that meat lipids also consist of these FA (Sinanoglou et al., 2013). The proportion of the BCFA group was found to be significantly lower $(P<0.001)$ in $\mathrm{P}$ lambs $\left(1.92{\mathrm{~g} 100 \mathrm{~g}^{-1}}^{-1}\right.$

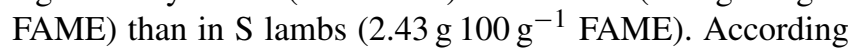
to Serra et al. (2009), BCFAs are indicators of rumen activity, and their proportion in meat increases with lamb weight and age. Findings from this study regarding BCFAs were comparable with those reported by Aurousseau et al. (2007a) for lambs in similar production systems (between 1.3 and

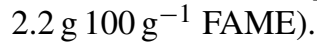

The ratios and indexes of FA groups as affected by production system are shown in Table 2. According to Sinanoglou et al. (2013), these ratios and indexes are important when assessing the nutrition value of lipids. The ratio of PUFA / SFA was significantly lower $(P<0.001)$ in $\mathrm{S}$ lambs $(0.12)$ than in $\mathrm{P}$ lambs (0.36), reflecting fact that PUFAs were significantly lower and SFAs were significantly higher in S lambs. Both ratios were lower than those recommended in the literature (above 0.7 - Raes et al., 2004 and Lanza et al., 2006 and 0.45 - Williams, 2000). Similar to findings from this study, Sanudo et al. (2000) reported PUFA / SFA ratios between 0.14 and 0.33 for Spanish Merino, Rasa Aragonesa, and Welsh Mountain lambs; Yousefi et al. (2012) reported values of 0.19 and 0.16 for lambs of two Iranian breeds. Conversely, Díaz et al. (2005) and Sinanoglou et al. (2013) reported the ratios of PUFA / SFA to be slightly higher $(0.38,0.20,0.19$, and 0.21 or between 0.37 and 0.49 ) than those found in $P$ and S lambs. The n- 6 / n-3 PUFA ratios were 1.86 (P lambs) and 2.23 (S lambs). Williams (2000) indicated that this ratio plays a significant role regarding the risk of atherosclerosis. A low n- 6 / n-3 PUFA ratio reduces the risk of many chronic diseases that mainly occur in Europe and North America populations (Simopoulos et al., 2008). The recommended n6/n-3 PUFA ratio value is a maximum of 4 (Raes et al., 2004; Howes et al., 2015); therefore, the values found in this study are desirable. When assessing the cholesterolaemic effect of lipids, the $h / H$ index may be useful due to the fact that it is related to cholesterol metabolism (Santos-Silva et al., 2013; Raes et al., 2003; Sinanoglou et al., 2013). The values of the $h / H$ index significantly differed $(P<0.001)$ between $\mathrm{P}$ lambs (1.30) and $\mathrm{S}$ lambs (0.90) in this study. In contrast, Santos-Silva et al. (2002) found no statistical difference $(P>0.05)$ in the $h / H$ index which ranged from 1.84 to 2.04; however, the value of this index also tended to be higher in lambs on pasture. The values of AI and TI significantly differed $(P<0.001)$ between $P$ lambs $(0.97$ and 1.24$)$ and $S$ lambs (1.58 and 2.13). According to Sinanoglou et al. (2013), $\mathrm{AI}$ and TI should not exceed 1.0. The values of AI found for P lambs agree with Vacca et al. (2008), who reported an AI value close to 1.0 for Sarda purebred and crossbred lambs; however the findings from this study were lower than Oriani et al. (2005), who reported a value of 1.35 for Merino lambs, and higher than Sinanoglou et al. (2013), who reported values from 0.55 to 0.73 for lambs from Greek breeds. Therefore, with respect to AI, the meat of P lambs would be considered a healthy food with a desirable FA composition, and its composition may help prevent cardiovascular diseases in consumers. The values of TI found in both P and S lambs were either higher than those reported by Vacca et al. (2008) and Sinanoglou et al. (2013), who mentioned TI values between 0.9 and 1.1 and between 0.83 and 1.21 , respectively, or were lower than those reported by Oriani et al. (2005), who mentioned a TI value of 1.69. However, Vacca et al. (2008), Sinanoglou et al. (2013), and Oriani et al. (2005) all evaluated the meat of suckling lambs.

\subsubsection{Effect of sex}

The proportions of the FA groups, their ratios, and indexes in dependence on sex are shown in Table 2 . The significant differences between males and females $(P<0.001 ; P<0.05)$ were seen in the proportions of CLA, MUFA, cisUFA, n-3 PUFA, and n-6 PUFA. Similarly to individual FAs, the differences in the proportions of FA groups may be explained by different male and female feeding behaviour and metabolism that results in differences in fat content. Arsenos et al. (2006) reported the significant effect $(P<0.05)$ of sex in only one (PUFA) out of four FA groups (SFA, UFA, MUFA, PUFA). Cividini et al. (2008) reported significant differences between males and females in MUFA, PUFA, n-6 PUFA, and n-3 PUFA. Similarly to this study (MUFA higher in females), the proportion of MUFA was found to be higher in JezerskoSolčava females than in males. However, in contrast to this study (no significant differences between sexes), the proportion of PUFA was found to be higher in Jezersko-Solčava males than in females.

In a similar fashion to the analyses of individual SFAs, the production system-sex interaction had a significant influence $(P<0.05)$ on the proportion of SFAs (considered as a group). Production system-sex interaction also had a significant influence on AI, TI, and the $h / H$ index. However, as no studies investigating the effect of production system-sex interaction currently exist in the literature, respective comparisons could not be carried out. 


\section{Conclusions}

From a nutrition and human health standpoint (with respect to higher proportions of PUFAs, e.g. mainly LC n-3 PUFA, CLA, and essential FA, and lower proportions of SFA), the meat of lambs assigned to pasture feeding with no concentrate supplement seems to be better than the meat of lambs assigned to grow in a stable with a diet based on hay, silage, and concentrates. Therefore, consumers are recommended to favour the meat of grazing lambs in spite of the fact that the market price of this meat may be higher owing to its higher quality.

Data availability. Data are available from the corresponding author upon request.

Author contributions. MM designed the experiment, performed the statistical analysis, and contributed to the paper. MO prepared the paper. JM obtained the meat samples. RK carried out the gas chromatography analyses.

Competing interests. The authors declare that they have no conflict of interest.

Acknowledgements. This work was supported by the Slovak Research and Development Agency (contract no. APVV-0458-10), the Research and Development Operational Programme funded by the ERDF, the Comenius University in Bratislava Science Park (grant no. ITMS 26240220086), and the Ministry of Education, Science, Research and Sport of the Slovak Republic (project VEGA 1/0364/15). Thanks are due to laboratory staff of the Institute of Chemistry (Faculty of Natural Sciences) at Comenius University in Bratislava and the staff of the slaughter houses (National Agricultural and Food Centre - Research Institute of Animal Production Nitra and Slovak University of Agriculture in Nitra).

Edited by: Steffen Maak

Reviewed by: four anonymous referees

\section{References}

Ackman, R. G.: The gas chromatograph in practical analyses of common and uncommon fatty acids for the 21 st century, Anal. Chim. Acta, 465, 175-192, 2002.

Arsenos, G., Kufidis, D., Zygoyiannis, D., Katsaounis, N., and Stamataris, C.: Fatty acid composition of lambs of indigenous dairy Greek breeds of sheep as affected by post-weaning nutritional management and weight at slaughter, Meat Sci., 73, 55-65, 2006.

Aurousseau, B., Bauchart, D., Calichon, E., Micol, D., and Priolo, A.: Effect of grass or concentrate feeding systems and rate of growth on triglyceride and phospholipid and their fatty acids in the M. longissimus thoracis of lambs, Meat Sci., 66, 531-541, 2006.
Aurousseau, B., Bauchart, D., Faure, X., Galot, A. L., Prache, S., Micol, D., and Priolo, A.: Indoor fattening of lambs raised on pasture: (1) Influence of stall finishing duration on lipid classes and fatty acids in the longissimus thoracis muscle, Meat Sci., 76, 241-252, 2007a.

Aurousseau, B., Bauchart, D., Galot, A. L., Prache, S., Micol, D., and Priolo, A.: Indoor fattening of lambs raised on pasture: (2) Influence of stall finishing duration on triglyceride and phospholipid fatty acids in the longissimus thoracis muscle, Meat Sci., 76, 417-427, 2007b.

Cividini, A., Levart, A., and Žgur, S.: Fatty acid composition of lamb meat as affected by production system, weaning and sex, Acta Agri. Slovenica, 2, 47-52, 2008.

Cividini, A., Levart, A., Žgur, S., and Kompan, D.: Fatty acid composition of lamb meat from the autochthonous Jezersko-Solčava breed reared in different production systems, Meat Sci., 97, 480485, 2014.

Costa, R. G., dos Santos, N. M., de Cássia Ramos do Egypto Queiroga, R., Madruga, M. S., and Quiroga Cartaxo, F.: Physicochemical characteristics and fatty acid profile of meat from lambs with different genotypes and diets, Rev. Bras. Zootec., 44, 248254, 2015.

Daley, C. A., Abbott, A., Doyle, P. S., Nader, G. A., and Larson, S.: A review of fatty acid profiles and antioxidant content in grassfed and grain-fed beef, Nutrition J., 9, 1-12, 2010.

Díaz, M. T., Velasco, S., Canegue, V., Lauzurica, S., Ruiz de Huidobro, F., Pérez, C., González, J., and Manzanarez, C.: Use of concentrate or pasture for fattening lambs and its effect on carcass and meat quality, Small Rum. Res., 43, 257-268, 2002.

Díaz, M. T., Álvarez, I., De la Fuente, J., Sanudo, C., Campo, M. M., Oliver, M. A., Font i Furnols, M., Montossi, F., San Julián, R., Nute, G. R., and Caneque V.: Fatty acid composition of meat from typical lamb production systems in Spain, United Kingdom, Germany and Uruguay, Meat Sci., 71, 256-263, 2005.

European Food Safety Authority: Scientific opinion on dietary reference values for fats, including saturated fatty acids, polyunsaturated fatty acids, monounsaturated fatty acids, trans fatty acids, and cholesterol, EFSA J., 8, 1461, 2010.

Fiori, M., Scintu, M. F., Sitzia, M. and Addis, M.: Dietary effects on meat chemical traits and fatty acid composition in intramuscular lipids of Sarda x Ile de France heavy lambs, Options Méditerranéennes, 107, 201-205, 2013.

Fisher, A. V., Enser, M., Richardson, R. I., Wood, J. D., Nute, G. R, Kurt, E., Sinclair, L. A., and Wilkinson, R. G.: Fatty acid composition and eating quality of lamb types derived from four diverse breed x production systems, Meat Sci., 55, 141-147, 2000.

Gallardo, M. A., Dannenberger, D. A., Rivero, J., Pulido, R., and Nuernberg, K.: Fatty acid profile of plasma, muscle and adipose tissues in Chilota lambs grazing on two different low quality pasture types in Chiloé Archipelago (Chile), Anim. Sci. J., 85, 935941, 2014.

Howes, N. L., Bekhit, A., Burritt D. J., and Campbell, A. W.: Opportunities and implications of pasture-based lamb fattening to enhance the long-chain fatty acid composition in meat, Comprehensive Rev. in Food Sci. and Food Safety, 14, 22-36, 2015.

Jenkins, T. C.: Regulation of lipid metabolism in the rumen, J. Nutrition, 124, 1372S-1376S, 1994. 
Komprda, T., Kuchtík, J., Jarošová, A., Dračková, E., Zemánek, L., and Filipčík, B.: Meat quality characteristics of lambs of three organically raised breeds, Meat Sci., 91, 499-505, 2012.

Lanza, M., Bella, M., Priolo, A., Barbagallo, D., Galofaro, V., Landi, C., and Pennisi, P.: Lamb meat quality as affected by a natural or artificial milk feeding regime, Meat Sci., 73, 313-318, 2006.

Margetín, M., Kališ, M., Čapistrák, A., Malík, J., and Kica, J.: Carcass evaluation of light lambs, Náš chov, 4, 176-177, 1993 (in Slovak).

Margetín, M., Apolen, D., Oravcová, M., Vavrišinová, K., Peškovičová, D., Luptáková, L., Krupová, Z., Bučko, O., and Blaško, J.: Fatty acids profile of intramuscular fat in light lambs traditionally and artificially reared, J. Central European Agri., 15, 117-129, 2014a.

Margetín, M., Margetínová, J., Oravcová, M., Luptáková, L., and Horečná, Z.: Carcass quality and physico-chemical characteristics of meat of light lambs, Acta Fyto. Zoo., 16, 83-89, 2014b.

McAfee, A. J., McSorley, E. M., Cuskelly, G. J., Moss, B. W., Wallace, J. M. W., Bonham, M. P., and Fearon, A. M.: Red meat consumption: An overview of the risks and benefits, Meat Sci., 84, 1-13, 2010.

Mel’uchová, B., Blaško, J., Kubinec, R., Górová, R., Dubravská, J., Margetín, M., Soják, L.: Seasonal variation in fatty acid composition of pasture forage plants and CLA content in ewe milk fat, Small Rum. Res., 78, 56-65, 2008.

Mel'uchová, B., Blaško, J., Kubinec, R., Górová, R., Michalec, M., Vargová, V., Kováčiková, Z., Margetín, M., and Soják, L.: Influence of floristic grazing cover on sheep milk quality, Acta Fyto. Zoo., 3, 57-64, 2009.

Milewski, S.: Health-promoting properties of sheep products, Med., Vet., 62, 516-519, 2006.

Mortimer, S. I., Van der Werf, J. H. J., Jacob, R. H., Hopkins, D. L., Pannier, L., Pearce, K. L. , Gardner, G. E., Warner, R. D., Geesing, G. H., Hocking Edwards J. E., Ponnampalam, E. N., Ball, A. J., Gilmour, A. R., and Pethick, D. W.: Genetic parameters for meat quality traits of Australian lamb meat, Meat Sci., 96, 1016-1024, 2014.

Nuernberg, K., Nuernberg, G., Ender, K., Dannenberger, D., Schabbel, W., Grumbach, S., Zupp, W., and Steinhart, H.: Effect of grass vs. concentrate feeding on the fatty acid profile of different fat depots in lambs, European J. Lipid Sci. Technol., 107, 737745,2005

Nuernberg, K., Fischer, A., Nuernberg, G., Ender, K., and Dannenberger, D.: Meat quality and fatty acid composition of lipids in muscle and fatty tissue of Skudde lambs fed grass versus concentrate, Small Rum. Res., 74, 279-283, 2008.

Oriani, G., Maiorano, G., Filetti, F., Di Cesare, C., Manchisi, A., and Salvatori, G.: Effect of age on fatty acid composition of Italian Merino suckling lambs, Meat Sci., 71, 557-562, 2005.

Pariza, M. W., Park, Y., and Cook, M. E.: The biologically active isomers of conjugated linoleic acid, Prog. Lipid Res., 40, 283 298, 2001

Ponnampalam, E. N., Butler, K. L., Pearce, K. M., Mortimer, S. I., Pethick D. W., Ball, A. J., and Hopkins, D.L.: Sources of variation of health claimable long chain omega-3 fatty acids in meat from Australian lamb slaughtered at similar weights, Meat Sci., 96., 1095-1110, 2014.
Raes, K., De Smet, S., and Demeyer D.: Effect of dietary fatty acids on incorporation of long chain polyunsaturated fatty acids and conjugated linoleic acid in lamb, beef and pork meat: a review, Animal Feed Sci. Technol., 113, 199-221, 2004.

Santos-Silva, J., Bessa, R. J. B., and Santos-Silva, F.: Effect of genotype, feeding system and slaughter weight on the quality of light lambs II., Fatty acid composition of meat, Livest. Prod. Sci., 77, 187-194, 2002.

Sanudo, C., Enser, M. E., Campo, M. M., Nute, G. R., María, G., Sierra, I., and Wood, J. D.: Fatty acid composition and sensory characteristics of lamb carcasses from Britain and Spain, Meat Sci., 54, 339-346, 2000.

SAS Institute Inc.: SAS/STAT 9.2 User's Guide, Second Edition, Cary, NC USA, 2009.

Schmid, D., Collomb, M., Sieber, R., and Bee, G.: Conjugated linoleic acid in meat and meat products: A review, Meat Sci., 73, 29-41, 2006.

Serra, A., Mele, M., La Comba, F., Conte, G., Buccioni, A., and Secchiari, P.: Conjugated Linoleic Acid (CLA) content of meat from three muscles of Massese suckling lambs slaughtered at different weights, Meat Sci., 81, 396-404, 2009.

Sharrow, S. H., Krueger, W. C., and Thetford, F. O.: Effects of stocking rate on sheep and hill pasture performance, J. Anim. Sci., 52, 210-217, 1981.

Silva Sobrinho, A. G., Cirne, L.G. A., and Santana, V. T.: Fatty acid profile of meat of lambs fed on diets containing mulberry hay, Eng. Technol. Int. J. Anim. Vet. Sci., 8, 466-468, 2014.

Simopoulos, A. P.: The importance of the ratio of omega-6/omega-3 essential fatty acids. Dossier: polyunsaturated fatty acids in biology and diseases, Biomed. and Pharmacotherapy, 56, 365-379, 2002.

Simopoulos, A. P.: The importance of the omega-6/omega-3 essential fatty acid ratio in cardiovascular disease and other chronic diseases, Exp. Biol. Med., 233, 674-688, 2008.

Sinanoglou, V. J., Batrinou, A., Mantis, F., Bizelis, I., and MiniadisMeimaroglou, S.: Lipid quality indices: Differentiation of suckling lamb and kid breeds reared by traditional sheep farming, Small Rum. Res., 113, 1-10, 2013.

Swanson, D., Block, R., and Mousa, S. A.: Omega-3 fatty acids EPA and DHA: Health benefits throughout life, Adv. Nutr., 3, $1-7,2012$.

Ulbricht, T. L. V. and Southgate, D. A. T.: Coronary heart disease seven dietary factors, The Lancet, 338, 985-992, 1991.

Vacca, G. M., Carcangiu, V., Dettori, M. L., Pazzola, M., Mura, M. C., Luridiana, S., and Tilloca, G.: Productive performance and meat quality of Mouflon x Sarda and Sarda x Sarda suckling lambs, Meat Sci., 80, 326-334, 2008.

Williams, C. M.: Dietary fatty acids and human health, Ann. Zootech, 49, 165-180, 2000.

Wood, J. D., Richardson, R. I., Nute, G. R., Fischer, A. V., Campo, M. M., Kasapidou, E., Sheard, P. R., and Enser, M.: Effects of fatty acids on meat quality: a review, Meat Sci., 66, 21-32, 2003.

Yousefi, A. R., Kohram, H., Shahneh, A. Z., Nik-Khah, A., and Campbell, A. W.: Comparison of the meat quality and fatty acid composition of traditional fat-tailed (Chall) and tailed (Zel) Iranian sheep breeds, Meat Sci., 92, 417-422, 2012. 